\section{A) Check for updates}

Cite this: Food Funct., 2020, 11, 955

\title{
Drying of African leafy vegetables for their effective preservation: the difference in moisture sorption isotherms explained by their microstructure
}

\author{
Leonie van't Hag, (D) a Jessica Danthe, ${ }^{a}$ Stephan Handschin, ${ }^{a}$ Gibson P. Mutuli, ${ }^{b}$ \\ Duncan Mbuge ${ }^{b}$ and Raffaele Mezzenga (D) *a,c
}

\begin{abstract}
The problem of malnutrition and nutrition deficiency, as well as droughts that lead to reduction in food supply and starvation, is well documented for Sub-Saharan Africa. Reducing post-harvest losses of five species of African leafy vegetables (ALVs) by preservation through drying is studied herein. Energy efficient gentle drying conditions using superabsorbent polymers and a temperature of $40^{\circ} \mathrm{C}$ were shown to preserve most leaf structures and vitamins. The microbial safe moisture content of the ALVs was found to be $\leq 14 \%$ dry basis. Dried Slender Leaf and Nightshade leaves could be rehydrated to the equilibrium moisture content of fresh leaves upon dry storage, while it was not possible for Jute Mallow, Cowpea and Amaranthus. This was attributed to different palisade parenchyma cell lengths. An increased amount of starch granules as observed in the microstructure of Cowpea and Nightshade leaves is suggested to explain their fibrous texture upon cooking. These results show that the ALVs can be effectively preserved using the same drying method and that this can be used to fight micro-nutrient deficiencies during droughts.
\end{abstract}

Received 3rd June 2019,

Accepted 1st January 2020

DOI: 10.1039/c9fo01175g

rsc.li/food-function
(Amaranthus) and Vigna unguiculata (Cowpea) were identified as promising foodstuff for addressing micronutrient deficiency, food security and up-scaling. Compared to other vegetables they are more resistant to diseases, are drought tolerant, yield well and are well accepted in Eastern Africa in terms of taste. ${ }^{5}$ Importantly, ALVs are highly nutritive, containing the recommended daily allowance of vitamin A, B2 (riboflavin) and C, iron and calcium, in only $100 \mathrm{~g}$ of fresh leaves. ${ }^{4,6}$

ALVs thrive well in the rainy season but are highly liable to degradation once harvested. Microbial contamination and toxicity commonly lead to post-harvest losses. ${ }^{6}$ One of the main microorganisms responsible for the formation of food toxins is Aspergillus flavus (A. flavus) which is a pathogenic fungus. Its highly toxic secondary metabolite aflatoxin B1 is estimated to be responsible for up to $28 \%$ of the cases of hepatocellular carcinoma, the most common form of liver cancer. ${ }^{7}$ In Kenya, outbreaks of aflatoxin poisoning have been reported in 1978, 1982 and annually between 2001 and 2012, leading to loss of human lives and destruction of tons of contaminated food. ${ }^{8}$ Drying of ALVs can address post-harvest losses due to reduced microbial contamination. ${ }^{9}$ Importantly, it was demonstrated that the consumption of sun-dried Cowpea and Amaranthus leaves improved the level of $\beta$-carotene and consequently vitamin A levels in children. ${ }^{10}$ Traditional sun drying methods, however, often yield poor results. ${ }^{9}$ This has become particu-

\footnotetext{
${ }^{a}$ Department of Health Sciences and Technology, ETH Zurich, Schmelzbergstrasse 9, CH-8092 Zurich, Switzerland. E-mail: raffaele.mezzenga@hest.ethz.ch

${ }^{b}$ Department of Environmental and Biosystems Engineering, University of Nairobi, P.O. Box 30196, 00100 G.P.O. Nairobi, Kenya

${ }^{c}$ Department of Materials, ETH Zurich, Schmelzbergstrasse 9, CH-8092 Zurich, Switzerland
} 
larly significant in recent years, since the weather has become more unpredictable and the rainy season often continues during the harvest time. ${ }^{7}$ A recent study by some of us showed that upon controlled drying at $40{ }^{\circ} \mathrm{C}$ the $\beta$-carotene levels (provitamin A) in Cowpea and Jute Mallow leaves was only reduced by $\sim 10 \%$, whereas drying at $100{ }^{\circ} \mathrm{C}$ caused a reduction of $35-50 \% .{ }^{11}$ The more hydrophilic vitamins $\mathrm{B} 2$ and $\mathrm{C}$ were also preserved significantly better at $40{ }^{\circ} \mathrm{C}$ (loss of only $15-20 \%$ and $25-40 \%$, respectively) compared to $100{ }^{\circ} \mathrm{C}$ (both loss of $\sim 50 \%) .{ }^{11}$ We will focus on controlled and gentle drying at $40{ }^{\circ} \mathrm{C}$ herein since especially there is widespread vitamin A deficiency in children.

The range of water activities at which pathogenic microorganisms cannot grow is crucial for determining safe preservation conditions of food. ${ }^{12}$ Water activity $\left(a_{\mathrm{w}}\right)$ is the partial pressure of water in food $(P)$ relative to the vapor pressure of pure water at the same temperature $\left(P_{0}\right) \cdot{ }^{13}$ Pathogenic bacteria are not able to grow at $a_{\mathrm{w}}<0.86$ while yeast and molds do not grow at $a_{\mathrm{w}}<0.62 .{ }^{14}$ For this reason, it is crucial to understand the moisture sorption characteristics of vegetables for effective preservation: this indicates the values of $a_{\mathrm{w}}$ for different equilibrium moisture contents. Moisture sorption isotherms of fresh and pre-dried leaves at $40{ }^{\circ} \mathrm{C}$ were used to determine the monolayer moisture content and microbial safe moisture content $\left(a_{\mathrm{w}}<0.6\right)$ of five species of ALVs.

The five species of ALVs used in this study are Corchorus olitorius (Jute Mallow), Crotalaria ochroleuca (Slender Leaf), Vigna unguiculata (Cowpea), Solanum villosum (Nightshade) and Amaranthus blitum (Amaranthus). Jute Mallow and Slender Leaf break down into a pasty (slimy) mass when cooked while Cowpea, Nightshade and Amaranthus are highly fibrous. These characteristics are representative of other ALV species in the particular groups and the soft matter analysis can give an indication of the behavior of other ALVs with similar compositions. In this study, we explain the observed differences in moisture sorption characteristics of the five different species using their microstructure. Thin and ultra-thin cross-sections of the leaves were investigated using brightfield microscopy and transmission electron microscopy (TEM) to analyze their microstructure. These results provide guidelines for the safe storage of ALVs during droughts, providing a good source of micro-nutrients and helping in fighting hidden hunger.

\section{Materials and methods}

\section{African leafy vegetables (ALVs)}

The ALV species used are Corchorus olitorius (Jute Mallow), Crotalaria ochroleuca (Slender Leaf), Vigna unguiculata (Cowpea), Solanum villosum (Nightshade) and Amaranthus blitum (Amaranthus). All seeds were obtained from Simlaw Seeds (Nairobi, Kenya), except for Cowpea seeds which were from East African Seeds Co. Ltd (Nairobi, Kenya). The five species were grown in a greenhouse (ETH, Zurich). The temperature was $25{ }^{\circ} \mathrm{C}$ from 6 a.m.-10 p.m. and $22{ }^{\circ} \mathrm{C}$ from 10 p.m. -6 a.m. The relative humidity was $60-70 \%$. Seeds were germinated in trays and one week after planting the seedlings were transferred to pots. Mature leaves were used for analysis (Fig. 1) which took four weeks to grow for Amaranthus, Nightshade and Cowpea and six weeks for Jute Mallow and Slender Leaf. The moisture content of fresh leaves was determined in triplicate using a Mettler Toledo HE53 halogen moisture analyzer (Greifensee, Switzerland).

\section{Sorption isotherm measurements and data analysis}

Dynamic Vapor Sorption (DVS) measurements were performed at $40{ }^{\circ} \mathrm{C}$ using a DVS-ET1 Surface Measurement System (London, UK). ${ }^{15}$ This was done by cutting $15-20 \mathrm{mg}$ of a fresh leaf or 4-6 $\mathrm{mg}$ of a pre-dried leaf into thin sections with a razor blade. Fresh leaves were conditioned for 12 hours at 95\% relative humidity $(\mathrm{RH})$ and $40{ }^{\circ} \mathrm{C}$. For the desorption isotherms, steps of $15 \% \mathrm{RH}$ were used down to $5 \%$ until the mass was stable $\left(\mathrm{d} m / \mathrm{d} t<0.0005 \mathrm{mg} \mathrm{min}^{-1}\right.$ or maximum time: $1000 \mathrm{~min}$ ), followed by $0 \% \mathrm{RH}$ for $1000 \mathrm{~min}$ ( 17 hours), and this was used as the reference mass. For the adsorption isotherms for the same samples the process was then reversed. For the pre-dried and stored leaves DVS analysis started with the adsorption isotherms and conditioning for 12 hours at $0 \%$ $\mathrm{RH}$ and $40{ }^{\circ} \mathrm{C}$ and this was used as the reference mass, followed by increasing the $\mathrm{RH}$ to $5 \%$ and then in steps of $15 \%$ (again until $\mathrm{d} m / \mathrm{d} t<0.0005 \mathrm{mg} \mathrm{min}^{-1}$ or a maximum time of $1000 \mathrm{~min}$ ) until $80 \% \mathrm{RH}$. The samples were then kept for $1000 \mathrm{~min}$ at $95 \% \mathrm{RH}$ followed by measuring a desorption isotherm using the same protocol. Pre-dried leaves were dried for 24 hours at $40{ }^{\circ} \mathrm{C}$ and stored in a sealed Petri dish for four to eight weeks (Jute Mallow: 5 weeks, Slender Leaf and Cowpea:

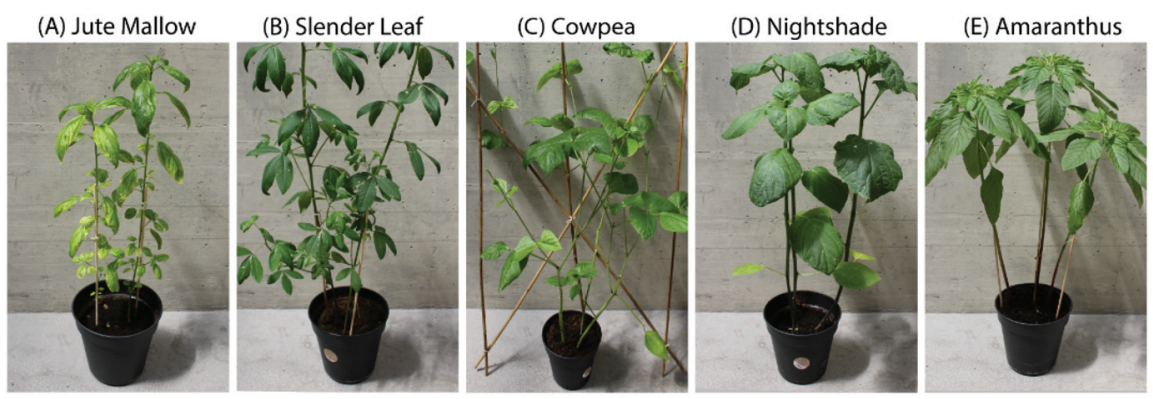

Fig. 1 Photographs of six-week-old plants: (A) Jute Mallow, (B) Slender Leaf, (C) Cowpea, (D) Nightshade and (E) Amaranthus. The pots are $13 \mathrm{~cm}$ high and their diameter $(\varnothing)$ is $15 \mathrm{~cm}$. 
Table 1 Moisture sorption isotherm models and equations used to determine their goodness of fit. In the models, $M_{\mathrm{e}}$ is the equilibrium moisture content and $a_{\mathrm{w}}$ the water activity where $a_{\mathrm{w}}=\frac{P}{P_{0}}=\frac{\text { relative humidity }}{100 \%} . A, B, C, M_{0}, K_{\mathrm{G}}$ and $k$ are the fitting parameters. In the equations for the model evaluation, $n$ is the number of data points, $M_{\text {predicted }}$ is the equilibrium moisture content as predicted by the model and $M_{\text {measured }}$ is the equilibrium moisture content obtained from the DVS data. SSE indicates the sum of squared errors, SST the total sum of squares and Res the residuals

\begin{tabular}{|c|c|c|}
\hline Model & Equation & Equation model evaluation \\
\hline Henderson & $M_{\mathrm{e}}=\left(\frac{\ln \left(1-a_{\mathrm{w}}\right)}{-A}\right)^{1 / B}$ & $\begin{array}{l}\left.\mathrm{SSE}=\sum\left(M_{i, \text { predicted }}-M_{i, \text { measured }}\right)^{2}\right)^{2} \\
\mathrm{SST}=\sum\left(M_{i, \text { measured }}-\bar{M}_{\text {measured }}\right)^{2} \\
\text { Res }=M_{i, \text { predicted }}-M_{i, \text { measured }}\end{array}$ \\
\hline Caurie & $\frac{1}{M_{\mathrm{e}}}=\frac{2}{M_{0} C}\left(\frac{1-a_{\mathrm{w}}}{a_{\mathrm{w}}}\right)^{2 C / M_{0}}$ & $\mathrm{RMSE}=\sqrt{\frac{\mathrm{SSE}}{n}}$ \\
\hline SIPS & $M_{\mathrm{e}}=K_{\mathrm{S}} \frac{a_{\mathrm{w}}{ }^{N}}{1+C a_{\mathrm{w}}^{N}}$ & $E(\%)=\frac{100}{n} \sum_{1}^{n} \frac{\mid \text { Res } \mid}{M_{i, \text { measured }}}$ \\
\hline GAB & $M_{\mathrm{e}}=\frac{M_{0} K_{\mathrm{G}} k a_{\mathrm{w}}}{\left(1-k a_{\mathrm{w}}\right)\left(1+\left(K_{\mathrm{G}}-1\right) k a_{\mathrm{w}}\right)}$ & $\chi^{2}=\sum_{1}^{n} \frac{\text { Res }^{2}}{M_{i, \text { measured }}}$ \\
\hline
\end{tabular}

4 weeks, Nightshade: 8 weeks and Amaranthus: 7 weeks). Their moisture content was determined to be $12-28 \%$ wet basis (w.b.) after storage.

Five different moisture sorption models (Table 1) were used to fit the DVS data with the non-linear least squares method (MATLAB, v. R2017a, MathWorks, Inc.). The models predict the equilibrium moisture content $\left(M_{\mathrm{e}}\right)$ as a function of the water activity $\left(a_{\mathrm{w}}\right)$ which is the relative partial pressure of water in the leaves $(P)$ compared to the vapor pressure of pure water at the same temperature $\left(P_{0}\right)$ as shown on the $x$-axes in Fig. 2 and 3 in percent (\%). Firstly, the Henderson equation is widely used to model sorption isotherms and the constants $A$ and $B$ depend on temperature and characterize the product. ${ }^{16}$ The other two-parameter model, the Caurie model, was derived to describe limited multilayer adsorption. $M_{0}$ is the monolayer moisture content and $C$ is the Caurie constant which is related to the heat of sorption. ${ }^{17,18}$ The other three models are threeparameter models. The modified Halsey equation provides an expression for multilayer condensation at a large distance from the surface. It takes the effect of temperature $(T)$ into account and further consists of the constants $A, B$ and $C .^{19}$ The SIPS isotherm model was developed for predicting systems with heterogeneous adsorption and it uses the sorption capacity $\left(K_{\mathrm{S}}\right)$, sorption intensity $(N)$ and energy of adsorption $(C){ }^{8}$ The Guggenheim-Anderson-de Boer (GAB) model is commonly used for food systems where $M_{0}$, the Guggenheim constant $\left(K_{\mathrm{G}}\right)$ related to the first layer of sorption and a constant $(k)$ describing the sorption of the multilayers characterize the samples. ${ }^{13,20}$
(A) Jute Mallow

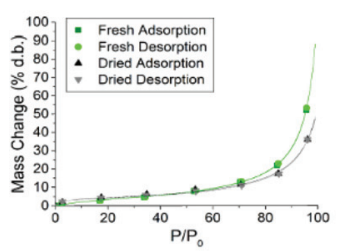

(F) Desorption Fresh

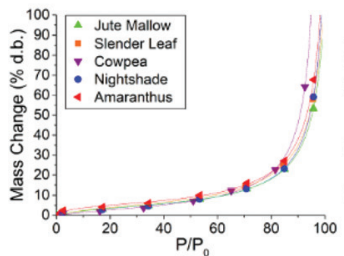

(B) Slender Leaf

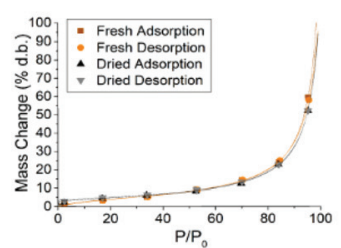

(G) Adsorption Dried

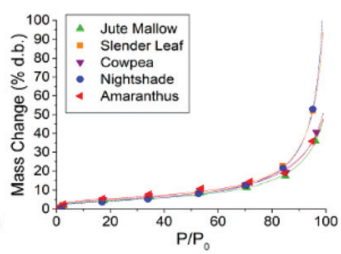

(C) Cowpea

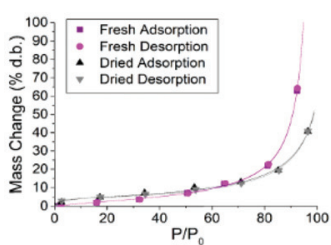

(H) 2-Parameter models

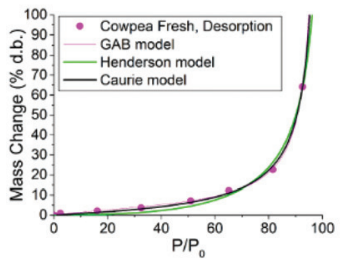

(D) Nightshade

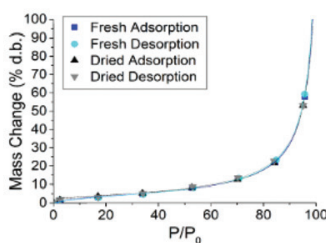

(I) Halsey model

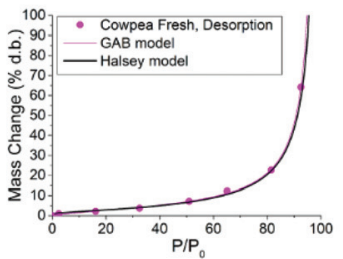

(E) Amaranthus

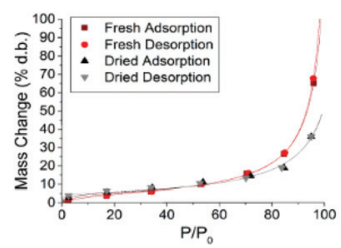

(J) SIPS model

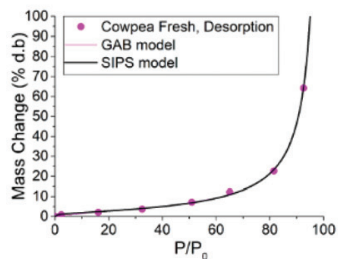

Fig. 2 Dynamic vapor sorption analysis of fresh (desorption isotherm followed by adsorption isotherm) and pre-dried and stored (adsorption isotherm followed by desorption isotherm) leaves of (A) Jute Mallow: dry storage 5 weeks, (B) Slender Leaf: dry storage for 4 weeks, (C) Cowpea: dry storage for 4 weeks, (D) Nightshade: dry storage for 8 weeks, and (E) Amaranthus: dry storage for 7 weeks. In (F) desorption isotherms of all the fresh leaves are compared as this characterizes their drying properties. In (G) the adsorption isotherms of the pre-dried and stored leaves are compared since this represents their rehydration capacity. Data in (A-G) are shown with a fit using the GAB model. Fitting of the desorption isotherm of the fresh Cowpea leaf with $(\mathrm{H})$ the 2-parameter Henderson and Caurie models, (I) the Halsey model and (J) the SIPS model is also shown. 
(A) Adsorption

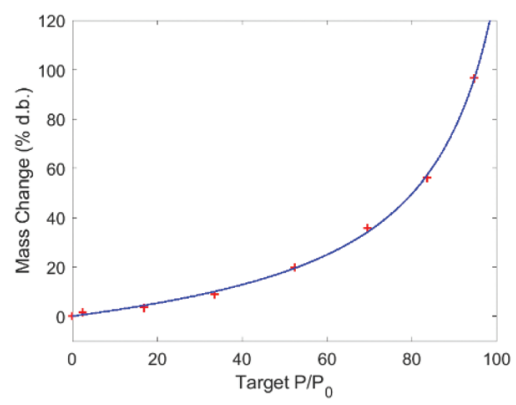

(B) Desorption

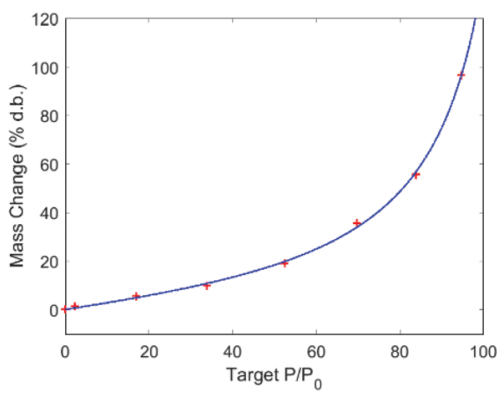

Fig. 3 Dynamic vapor sorption analysis of superabsorbent polymer Luquafleece fabric at $40^{\circ} \mathrm{C}$. (A) Adsorption isotherm followed by (B) desorption isotherm. Data are shown with a fit using the GAB model and fitting parameters are reported in Table 4.

The goodness of fit for the five different models was evaluated with the root mean square error (RMSE), coefficient of determination $\left(R^{2}\right)$, mean relative deviation modulus $(E \%)$ and chi-square test $\left(\chi^{2}\right)$, Table 1 . The RMSE determines the average error based on the sum of squared errors. ${ }^{21} R^{2}$ indicates the percentage of variability in the dependent variable and adopts values from zero to one, where one represents a perfect fit. ${ }^{22} E \%$ is widely used to assess sorption model evaluation and indicates a tendency to over- or underestimate the experimental data. A value below $10 \%$ is indicative of a good fit and a value below $5 \%$ an excellent fit. ${ }^{23-25} \chi^{2}$ indicates the similarity between the predicted and measured data where small values indicate a good fit and large values represent significant variation. ${ }^{22}$

\section{Light- and electron microscopy of thin and ultra-thin cross- sections of leaves}

Dried and stored samples were dried for 24 hours (48 hours for Cowpea and Amaranthus since their weight was not stable within 24 hours) at $40{ }^{\circ} \mathrm{C}$ and stored in a sealed Petri dish for three to six weeks (Jute Mallow, Slender Leaf and Nightshade: 3 weeks, and Cowpea and Amaranthus: 6 weeks). For light microscopy analysis they were rehydrated in 0.1 M PBS buffer ( $\mathrm{pH} 7, \mathrm{KH}_{2} \mathrm{PO}_{4}: \mathrm{Na}_{2} \mathrm{HPO}_{4}, 2: 3$ ) for 18-28 hours and degassed for 20 minutes under vacuum in buffer ( 10 mbar). Fresh leaves were also degassed in this way and with the same buffer before sectioning. Degassing under vacuum was done for the microscopy samples in order to obtain a relatively homogeneous refractive index in the sample. Thin cross-sections of $\sim 100 \mu \mathrm{m}$ thickness for light microscopy were obtained using a hand microtome (Leica, Germany). Small pieces of degassed leaves of around $10 \times 5 \mathrm{~mm}$ were placed in a sliced piece of fine pored Styrofoam. For dried leaves a piece of ACLAR-fluoropolymer film (EMS Electron Microscopy Sciences, USA) was sandwiched by two of the leaves as a mechanical support before cutting. The cut slices of the leaves were immediately soaked in PBS buffer and covered with a cover glass. Brightfield imaging was done with a $20 \times$ objective on a Zeiss AxioScope A1 microscope (Feldbach, Switzerland).

Ultrathin cross-sections of $\sim 50 \mathrm{~nm}$ thickness for TEM after chemical fixation and embedding were obtained from fresh and dried leaves upon rehydration for $\sim 24$ hours followed by degassing in $0.1 \mathrm{M}$ PBS buffer ( $\mathrm{pH} 7$ ) for 20 minutes under vacuum as described for the thin sections. For dried samples, the leaves were again dried for 24 hours (48 hours for Cowpea since the weight was not stable within 24 hours) at $40^{\circ} \mathrm{C}$ and stored in a sealed Petri dish for two weeks. Sample processing for chemical fixation of the hydrated leaves was done in a PELCO BioWave, Pro+ microwave system (Ted Pella, USA), following a microwave-assisted fixation and dehydration procedure. Fixation was done in $2.5 \%$ glutaraldehyde/2\% paraformaldehyde in 0.1 M PBS buffer ( $\mathrm{pH}$ 7) followed by postfixation in $1 \%$ osmium tetroxide $\left(\mathrm{OsO}_{4}\right)$ in $0.1 \mathrm{M}$ PBS ( $\left.\mathrm{pH} 7\right)$. After washing in the same PBS buffer once and twice in dd$\mathrm{H}_{2} \mathrm{O}$ post-fixation was done in 1\% uranyl acetate (UA), followed by washing in dd $-\mathrm{H}_{2} \mathrm{O}$ three times. Dehydration was done in a graded series of ethanol $(50 \%, 60 \%, 70 \%, 80 \%, 90 \%, 96$ and $100 \%$ ) on ice. For embedding, Spurr's resin at $25 \%$ in ethanol was used twice. The embedding in 50\% (twice: 2 hours at room temperature), $75 \%(2 \mathrm{~h}$ at room temperature and then overnight at $4{ }^{\circ} \mathrm{C}$ ) and $100 \%$ (three times: 2, 4, 2 hours) was performed without microwave-assistance. Polymerization was performed at $60{ }^{\circ} \mathrm{C}$ for 48 hours. Ultrathin sections ( $\left.\sim 50 \mathrm{~nm}\right)$ were cut on a Leica Ultracut FC6 (Leica Microsystems, Vienna, Austria), transferred on formvar coated carbon-grids (Quantifoil, Germany) and post-stained with uranyl acetate and lead citrate. Imaging was performed in a Morgagni 268 TEM (Thermo Fisher Scientific, USA) operated at $100 \mathrm{kV}$. Slight shading of images in Fig. 5(A, B and D, fresh) was corrected in Photoshop.

\section{Results and discussion}

\section{Moisture content and moisture sorption isotherms of the leaves}

Moisture sorption isotherms of fresh and pre-dried leaves at $40{ }^{\circ} \mathrm{C}$ were used to determine the monolayer moisture content and microbial safe moisture content $\left(a_{\mathrm{w}}<0.6\right)$ of the five species of ALVs. The moisture contents of mature leaves of the five ALV species are shown in Table 2. The moisture content of the leaves was $75 \%$ w.b. for Jute Mallow and Amaranthus and 
Table 2 Moisture content of the five species of ALVs in percent wet basis (\% w.b.) and percent dry basis (\% d.b.), and the standard deviation of triplicate measurements

\begin{tabular}{lll}
\hline & MC (\% d.b.) & MC (\% w.b.) \\
\hline Jute Mallow & $282 \pm 42$ & $74 \pm 3$ \\
Slender Leaf & $565 \pm 130$ & $85 \pm 3$ \\
Cowpea & $509 \pm 44$ & $84 \pm 1$ \\
Nightshade & $471 \pm 99$ & $82 \pm 3$ \\
Amaranthus & $313 \pm 29$ & $76 \pm 2$
\end{tabular}

$84 \%$ w.b. for Slender Leaf, Cowpea and Nightshade leaves. This represents $\sim 300 \%$ dry basis (d.b.) for Jute Mallow and Amaranthus and $\sim 500 \%$ d.b. for Slender Leaf, Cowpea and Nightshade. The values for Cowpea and Jute Mallow are in agreement with the results from a previous study. ${ }^{7}$

Dynamic vapor sorption analysis of the five species of ALV plants at $40^{\circ} \mathrm{C}$ is shown in Fig. 2(A-E). For each of the species the desorption and adsorption isotherms of fresh leaves are shown, as well as the adsorption (rehydration) and desorption isotherms of pre-dried and stored leaves. All curves can be described as Type II, with a sigmoidal shape, according to the Brunauer classification which is based on the van der Waals adsorption of gases on solid substrates. ${ }^{26}$ This shape is typical of moisture sorption isotherms of food that is low in sugar and has also been observed for leaves of other plant species. ${ }^{13,27-29}$ At high relative humidities $\left(P / P_{0}\right)$ excess water is present in the leaves which can behave as bulk water; from $P / P_{0} \sim 20-70 \%$ water is present in multilayers weakly bound to the solid, and from $P / P_{0} \sim 0-20 \%$ water is strongly bound and represents adsorption of the monolayer of water which is not available for chemical and deteriorative reactions. Hysteresis is defined as the difference in equilibrium moisture contents between the adsorption and desorption isotherms, and is often observed as delayed desorption for food samples due to water trapped in capillaries. ${ }^{13}$ Hysteresis was not observed for the fresh and pre-dried samples of the five ALV species suggesting that dehydration to a significantly lower moisture content already occurs at high relative humidities. For quantification, the data fitting results in the next sub-sections are used.

For Slender Leaf (Fig. 2(B)) and Nightshade (Fig. 2(D)) the moisture sorption isotherms of pre-dried and stored leaves were equal to those of the fresh leaves indicating complete rehydration of leaves that were stored dry for 4-8 weeks. We have confirmed for Slender Leaf that dry storage for four weeks (Fig. 2(B)) and nine weeks resulted in identical moisture sorption isotherms. At high relative humidities the moisture content of pre-dried and stored Jute Mallow (Fig. 2(A)), Cowpea (Fig. 2(C)) and Amaranthus (Fig. 2(E)) leaves was lower than that for the fresh leaves. This suggests that physical (e.g. structural) or chemical changes occurred during storage resulting in a modified material and therefore no complete rehydration of these species. Differences between the five species are directly compared and shown in Fig. 2(F and G) for the desorption isotherms of fresh leaves and adsorption isotherms (rehy- dration) of pre-dried and stored leaves. No significant changes were observed in the desorption characteristics of the five species indicating that both fibrous and slimy species can be dried for preservation with the same protocol. Jute Mallow, Cowpea and Amaranthus, however, did not rehydrate to the same level after being stored dry. There was no correlation between the equilibrium moisture content of the five species as obtained with the moisture sorption isotherms and the moisture content of the fresh leaves (Table 2).

Five different empirical and semi-empirical models were used to model the moisture sorption isotherms (Table 1). The best fit with each of these models is shown for the desorption isotherm of a fresh Cowpea leaf in Fig. $2(\mathrm{H}-\mathrm{J})$ as an example. The goodness of fit parameters for the four moisture sorption isotherms of Cowpea are shown in Table 3. The two-parameter $\left(p_{1}\right)$ Henderson and Caurie models did not fit the data as well as the three-parameter $\left(p_{2}\right)$ Halsey and GAB models. The $F$-test with $p=0.05$ and $F=\frac{\frac{\mathrm{SSE}_{1}-\mathrm{SSE}_{2}}{p_{2}-p_{1}}}{\frac{\mathrm{SSE}_{2}}{n-p_{2}}}$ also showed that the GAB model resulted in a significantly better fit for the Cowpea data ( $F=11-80$ which is larger than the critical $F$-value of 6.6) compared to the Henderson and Caurie models for the majority (6/8) of data sets shown in Table 3. The exceptions were the fits of the adsorption and desorption curves of dried Cowpea ( $F=-3 \& 5)$ with the Caurie model. Additionally, the SIPS model did not result in a good fit for the dried Cowpea leaves

Table 3 Goodness of fit parameters for the sorption isotherms of Cowpea leaves. Ads. indicates the adsorption isotherms of fresh and pre-dried and stored leaves and Des. indicates the desorption isotherms of the fresh and pre-dried and stored leaves. Results for the Henderson, Caurie, Halsey, SIPS and GAB models are shown and all equations can be found in Table 1. Values in bold and italic indicate a relatively poor fit: RMSE $>1, R^{2}<0.995, E \%>10 \%$ or $\chi^{2}>1$

\begin{tabular}{llllll}
\hline \multirow{5}{*}{ Model } & & \multicolumn{3}{l}{ Cowpea } & \\
\cline { 3 - 6 } & Parameters & $\begin{array}{l}\text { Fresh } \\
\text { ads. }\end{array}$ & $\begin{array}{l}\text { Fresh } \\
\text { des. }\end{array}$ & $\begin{array}{l}\text { Dried } \\
\text { ads. }\end{array}$ & $\begin{array}{l}\text { Dried } \\
\text { des. }\end{array}$ \\
\hline \multirow{6}{*}{ Henderson } & RMSE & $\mathbf{2 . 1 0}$ & $\mathbf{2 . 1 0}$ & $\mathbf{2 . 0 5}$ & $\mathbf{2 . 1 5}$ \\
& $R^{2}$ & $\mathbf{0 . 9 8 9}$ & $\mathbf{0 . 9 8 9}$ & $\mathbf{0 . 9 8 9}$ & $\mathbf{0 . 9 8 9}$ \\
& $E(\%)$ & $\mathbf{4 0 . 4 3}$ & $\mathbf{4 0 . 1 9}$ & $\mathbf{2 6 . 5 3}$ & $\mathbf{2 7 . 9 0}$ \\
& $\chi^{2}$ & $\mathbf{5 . 6 2}$ & $\mathbf{5 . 8 7}$ & $\mathbf{4 . 9 7}$ & $\mathbf{6 . 2 3}$ \\
& RMSE & 0.94 & 0.92 & 0.49 & 0.75 \\
& $R^{2}$ & 0.998 & 0.998 & 0.999 & 0.999 \\
& $E(\%)$ & $\mathbf{1 8 . 8 5}$ & $\mathbf{1 9 . 5 3}$ & 6.61 & 10.20 \\
& $\chi^{2}$ & $\mathbf{1 . 0 4}$ & $\mathbf{1 . 2 4}$ & 0.30 & $\mathbf{1 . 0 1}$ \\
& RMSE & 0.66 & 0.60 & 0.62 & 0.30 \\
& $R^{2}$ & 0.999 & 0.999 & 0.999 & 1.000 \\
& $E(\%)$ & 14.78 & 8.98 & 9.62 & 2.85 \\
& $\chi^{2}$ & 0.64 & 0.35 & 0.92 & 0.09 \\
& RMSE & 0.63 & 0.57 & $\mathbf{1 . 6 4}$ & $\mathbf{1 . 5 6}$ \\
& $R^{2}$ & 0.999 & 0.999 & $\mathbf{0 . 9 9 3}$ & $\mathbf{0 . 9 9 4}$ \\
& $E(\%)$ & 12.52 & 7.82 & $\mathbf{1 7 . 2 8}$ & $\mathbf{1 9 . 2 7}$ \\
& $\chi^{2}$ & 0.49 & 0.30 & $\mathbf{2 . 4 4}$ & $\mathbf{2 . 9 2}$ \\
& RMSE & 0.51 & 0.51 & 0.82 & 0.53 \\
& $R^{2}$ & 0.999 & 0.999 & 0.996 & 0.998 \\
& $E(\%)$ & 10.46 & 11.61 & 6.40 & 4.67 \\
& $\chi^{2}$ & 0.37 & 0.53 & 0.47 & 0.22
\end{tabular}


Table 4 GAB model fitting parameters for all DVS curves and their fits as shown in Fig. $2(\mathrm{~A}-\mathrm{G})$ and $3 . M_{0}$ is the monolayer moisture content, $K_{\mathrm{G}}$ the Guggenheim constant related to the first layer of sorption and $k$ a constant related to the sorption of the multilayers

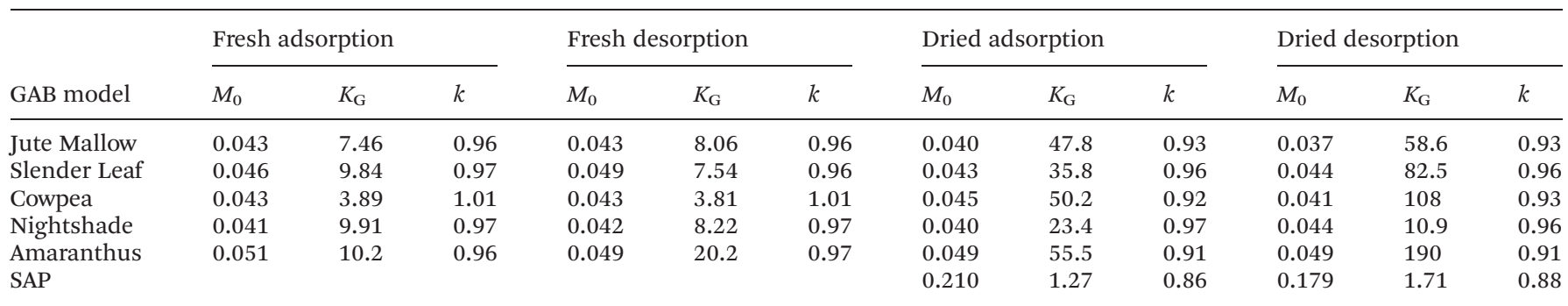

and different combinations of the SIPS fitting parameters could lead to the same fitting result. For this reason, the obtained values for the sorption capacity $\left(K_{\mathrm{S}}\right)$, sorption intensity $(N)$ and energy of adsorption $(C)$ could not be interpreted. Since the Halsey model uses fitting parameters with no physical meaning, the equally well performing GAB model is used herein to interpret the DVS data.

The fitting parameters for the GAB model for each of the DVS curves in Fig. 2 are shown in Table 4. The monolayer moisture content $M_{0}$ was determined to be $3.7-4.9 \%$ d.b. for all species. Similar values of $M_{0}$ were obtained with the Caurie model (3.6-6.5\% d.b.). This strongly bound moisture does not participate in deteriorative reactions. The Guggenheim constant $\left(K_{\mathrm{G}}\right)$ is related to the first layer of sorption and determined from the low relative humidity $\left(P / P_{0}<20 \%\right)$ region of the moisture sorption isotherms. Differences in $K_{\mathrm{G}}$ were significantly larger between sample treatments than between species. For pre-dried and stored leaves, values of $K_{\mathrm{G}}$ are an order of magnitude (23-190) larger than those for fresh leaf samples (4-20). The increased moisture sorption at the lowest relative humidities for dried leaves can also be seen in Fig. 2 (A-E). This is expected to be caused by chemical changes during storage. The constant describing water sorption of the multilayers $(k)$ is lower for pre-dried leaves of Jute Mallow, Cowpea and Amaranthus than those for their fresh leaves. This is represented by the reduced moisture content for these samples at high relative humidities (Fig. 2(A, C and E)). This is again expected to be due to chemical and structural changes during storage as investigated and confirmed by using microscopy in the next sub-section. The microbial safe moisture content of the African leafy vegetables $\left(a_{\mathrm{w}}<0.6\right)$ was determined using the GAB model and found to be $\leq 14 \%$ d.b.

The DVS data in Fig. 2 show that the ALVs already significantly increase their moisture content above $60 \% \mathrm{RH}$. Considering that the relative humidity in sub-Saharan Africa is in the range of $70-80 \%$ for most of the year, we suggest using superabsorbent polymers (SAP) to lower the moisture content of air in a standard convective dryer during dehydration at gentle temperatures $\left(40^{\circ} \mathrm{C}\right)$ and to use SAP to ensure storage of the ALVs below the microbial safe moisture content. DVS data of SAP Luquafleece fabric (BASF, Germany) are shown in Fig. 3 and it readily adsorbs moisture over the entire water activity range, including $<60 \%$ RH (Table $4: M_{0} \sim 20 \%$ d.b. and significantly higher than those for the ALVs). Additionally, the desorption curve in (B) shows that this process is completely reversible and that the SAP can be effectively reused for energy efficient drying. Efficient SAP-drying of an edible African crop has already been demonstrated by us in the case of maize. ${ }^{7}$

\section{Microstructure leaves}

The microstructure of the five species of ALVs was investigated using brightfield microscopy on cross-sections of $\sim 100 \mu \mathrm{m}$ thickness, Fig. 4. Fresh Jute Mallow, Slender Leaf, Cowpea and Nightshade leaves show long palisade parenchyma cells (top half in the images) and the spongy tissue (bottom half in the images) with the epidermis layer on the surfaces. This is a typical cellular organization for plants that utilize the Calvin cycle $\left(\mathrm{C}_{3}\right.$ cycle $)$ for photosynthesis. The cross-section of Cowpea shows that it has significantly thicker leaves $(327 \pm$ $18 \mu \mathrm{m}$ : all thicknesses were analysed in triplicate using ImageJ) than the other species $(130-200 \mu \mathrm{m})$ with significantly longer palisade cells $(187 \pm 12 \mu \mathrm{m}$ compared to $42-80 \mu \mathrm{m})$. Amaranthus has bundle sheath cells between the palisade cells and spongy tissue as part of the Krans leaf anatomy that is typical of $\mathrm{C}_{4}$ plants. $\mathrm{C}_{4}$ plants exhibit more efficient photosynthesis and the chloroplasts are present in a significantly higher concentration within the bundle sheath cells. For all five species, the round chloroplasts are clearly visible close to the cell walls. For Jute Mallow, rectangular crystals, as confirmed using crossed-polarizers, were observed in the nerves. We suggest that these are calcium oxalate crystals which are considered an anti-nutrient since they reduce the calcium that is available for nutritional adsorption. Oxalate crystals play a role in metal detoxification and calcium regulation in plants. $^{30,31}$

The microstructure of the rehydrated leaves shows significant differences in all five species. Palisade parenchyma and spongy parenchyma could still be distinguished. The shape of the cells, however, was distorted and the palisade cells were significantly shorter (Cowpea: $77 \pm 9 \mu \mathrm{m}$ and Jute Mallow, Slender Leaf and Nightshade: $36-55 \mu \mathrm{m}$ ). The final thickness of the rehydrated Cowpea and Jute Mallow leaves was reduced to $\sim 75 \%$ compared to that of the fresh leaves. For Slender Leaf, Nightshade and Amaranthus, however, the final thickness of the rehydrated leaves was similar to that of the fresh leaves. It is shown in Fig. 5 that the kinetics of dehydration 
(A) Jute Mallow

Fresh

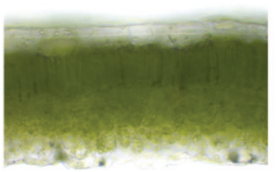

Rehydrated

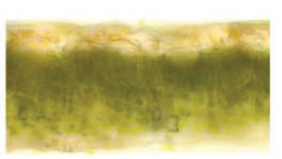

(B) Slender Leaf

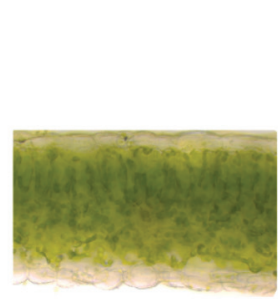

(C) Cowpea
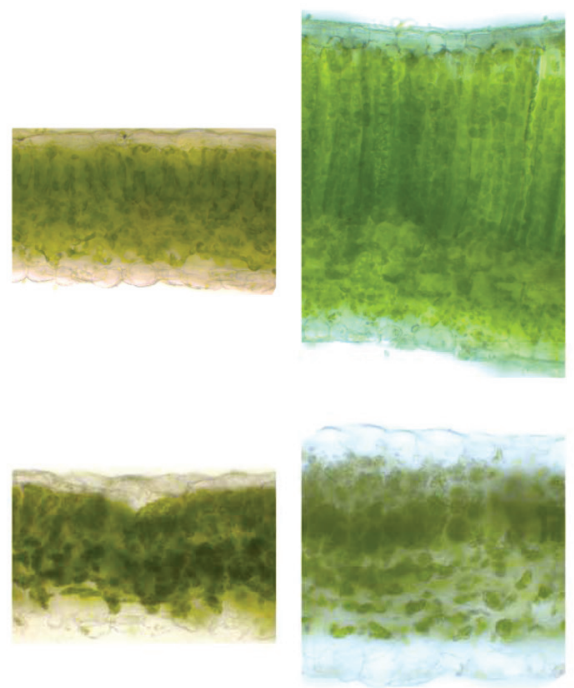

(D) Nightshade

(E) Amaranthus

Fig. 4 Light microscopy images of cross-sections $(\sim 100 \mu \mathrm{m})$ of (A) Jute Mallow: dry storage for 3 weeks, (B) Slender Leaf: dry storage for 3 weeks, (C) Cowpea: dry storage for 6 weeks, (D) Nightshade: dry storage for 3 weeks, and (E) Amaranthus: dry storage for 6 weeks. The top row shows the fresh leaves and the bottom row shows rehydrated leaves that were dried at $40{ }^{\circ} \mathrm{C}$ and stored. The scale bar of $50 \mu \mathrm{m}$ is for all images.

(A) Dehydration fresh 95\% RH

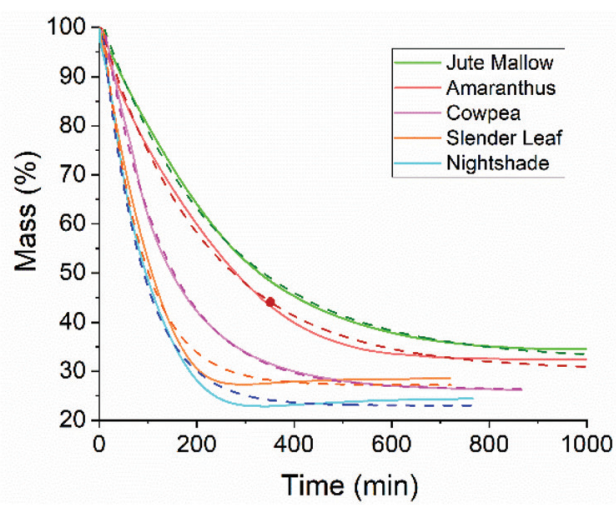

(B) Rehydration dried $85-95 \% \mathrm{RH}$

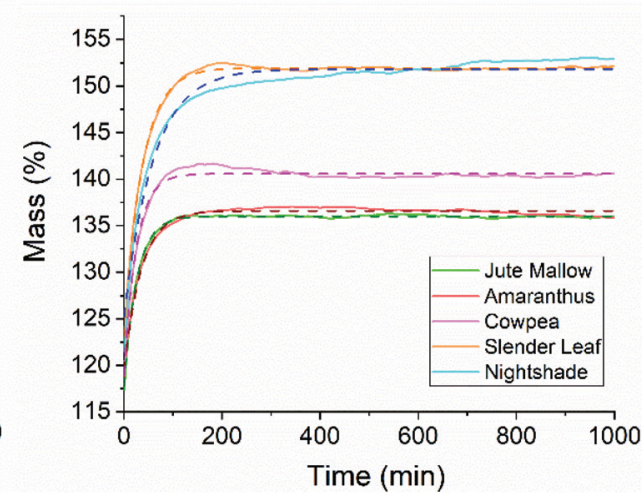

(C) Fitting parameters exponential decay and increase rates

\begin{tabular}{l|cccc|cccc}
\hline & \multicolumn{5}{|c|}{ Dehydration fresh } & \multicolumn{3}{c}{ Rehydration dried 85 - 95\% RH } \\
\hline & $\mathbf{R 1}$ & $\mathbf{A 1}$ & $\mathbf{y 1}$ & $\mathbf{R}^{\mathbf{2}}$ & $\mathbf{R 2}$ & $\mathbf{A 2}$ & $\mathbf{Y 2}$ & $\mathbf{R}^{\mathbf{2}}$ \\
\hline Jute Mallow & $\mathbf{2 4 3} \pm 0.3$ & $70 \pm 0.04$ & $32 \pm 0.02$ & 0.998 & $\mathbf{2 7} \pm 0.05$ & $-18 \pm 0.02$ & $136 \pm 0.002$ & 0.996 \\
\hline Slender Leaf & $80 \pm 0.3$ & $80 \pm 0.2$ & $27 \pm 0.04$ & 0.987 & $37 \pm 0.06$ & $-29 \pm 0.03$ & $152 \pm 0.003$ & 0.996 \\
\hline Cowpea & $126 \pm 0.1$ & $80 \pm 0.05$ & $26 \pm 0.01$ & 0.998 & $\mathbf{2 5} \pm 0.12$ & $-22 \pm 0.08$ & $141 \pm 0.006$ & 0.964 \\
\hline Nightshade & $81 \pm 0.2$ & $83 \pm 0.1$ & $23 \pm 0.03$ & 0.992 & $60 \pm 0.3$ & $-27 \pm 0.09$ & $152 \pm 0.01$ & 0.962 \\
\hline Amaranthus & $215 \pm 0.4$ & $71 \pm 0.06$ & $30 \pm 0.03$ & 0.996 & $35 \pm 0.13$ & $-17 \pm 0.04$ & $137 \pm 0.004$ & 0.980 \\
\hline
\end{tabular}

Fig. 5 Kinetics of $(\mathrm{A})$ dehydration of fresh leaves at $95 \% \mathrm{RH}$ and $(\mathrm{B})$ rehydration of dried leaves at $85-95 \% \mathrm{RH}$. The dashed lines show the fits of the data with a single exponential: Mass $(\%)=A \exp \left(-\frac{t}{R}\right)+y_{0}$ which were obtained using Origin 2018. (C) A table with all fitting parameters. The significantly affected rate constants $(R 1$ and $R 2)$ for Jute Mallow and Cowpea are indicated in bold. For Slender Leaf and Nightshade, the rate constants for the dehydration of fresh leaves and rehydration of dried leaves are similar. 


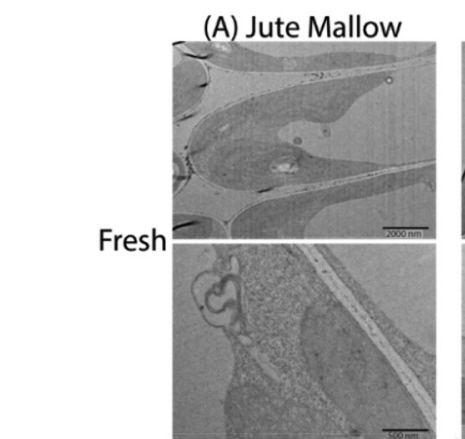

(B) Slender Leaf
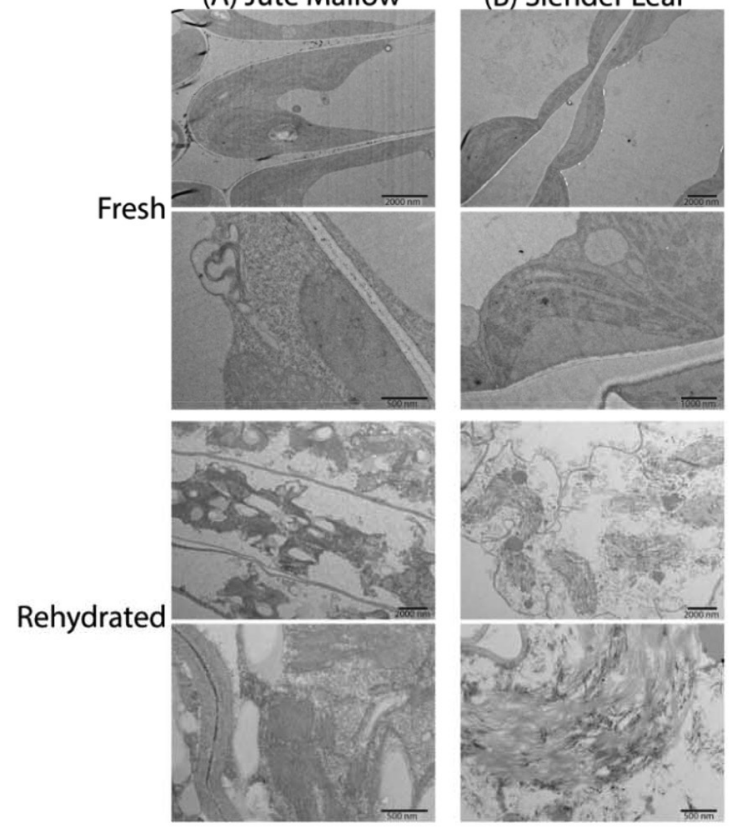

(C) Cowpea
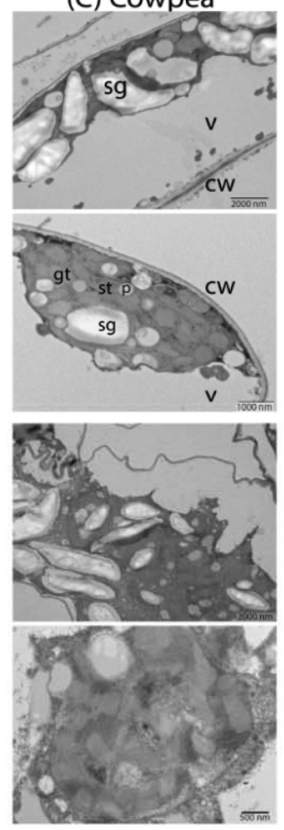

(D) Nightshade
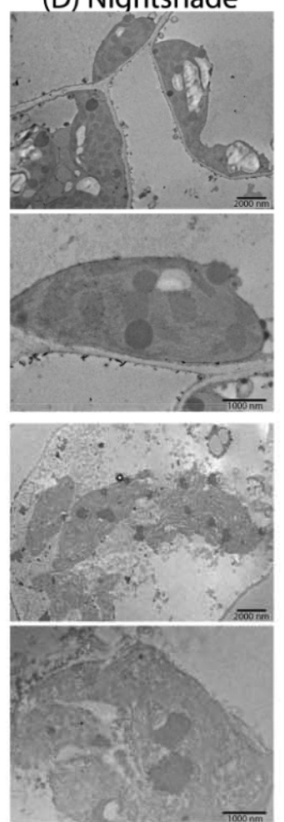

(E) Amaranthus
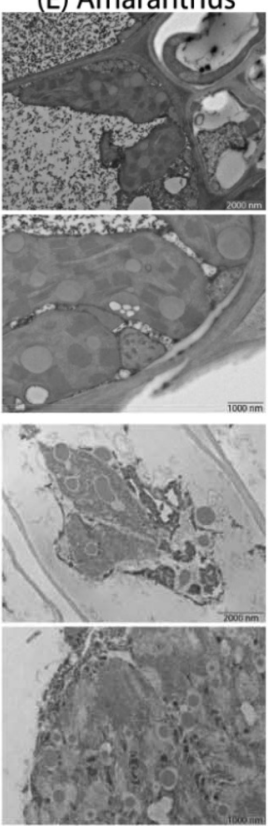

Fig. 6 TEM images of ultra-thin cross-sections ( $50 \mathrm{~nm}$ ) of (A) Jute Mallow, (B) Slender Leaf, (C) Cowpea, (D) Nightshade and (E) Amaranthus. The top two rows show the fresh leaves and the bottom two rows show rehydrated leaves that were dried at $40{ }^{\circ} \mathrm{C}$ and stored for 2 weeks. In all images chloroplasts with thylakoid membranes are visible as well as starch granules in most images. For the cross-section of the fresh cowpea leaves, the cell organelles are indicated as an example: cw indicates cell wall, gt is grana thylakoid, st is stroma thylakoid, p is plastoglobulus, sg indicates starch granule and $v$ is central vacuole.

and rehydration was also most significantly impacted (rate constants: $R$ ) for the species with the greatest parenchyma wall damage. Cell compartmentation was also partly lost through drying and individual round chloroplasts could not be observed in rehydrated leaves. The chlorophyll appears to be distributed throughout the cells as was also confirmed using confocal microscopy using chlorophyll auto-fluorescence (data not shown). The chlorophyll content and significantly altered chloroplast structures have also been reported for desiccant-tolerant plant species in the literature. ${ }^{32,33}$ For Jute Mallow, oxalate crystals were also observed in rehydrated leaves but the relative oxalate concentrations could not be quantified and compared.

To investigate the microstructure of the fresh and rehydrated cells of the ALV species more in detail we used TEM of ultra-thin cross-sections of $\sim 50 \mathrm{~nm}$ thickness from chemically fixed and embedded samples: Fig. 6 shows representative images. Cells of the fresh leaves showed well-organized peripheral chloroplast structures near the cell walls $(\mathrm{cw})$ with grana (gt) and stroma (st) thylakoid membranes and plastoglobuli (p, lipid rich granules). Furthermore, they showed a large central vacuole (v). As an example, the plant cell organelles are indicated for cross-sections of the fresh Cowpea leaf shown in Fig. 6(C). For cross-sections of the fresh Amaranthus leaf lead crystals due to post-staining are visible in the images. Cowpea and Nightshade showed a significantly larger amount of starch granules (sg) in their microstructure, which may explain their fibrous structure upon cooking compared to the paste that is formed by Slender Leaf and Jute Mallow. Starch granules can gelatinize and swell at high temperatures (above $\sim 68^{\circ} \mathrm{C}$ ) and give these leaves a firmer texture with less free water upon cooking. ${ }^{34}$ For Amaranthus, the starch granules may be concentrated in the bundle sheath cells ${ }^{32}$ and are not visible in the images shown herein.

The microstructure of the rehydrated leaves again showed significant differences compared to the fresh leaves for all five species. Firstly, the chloroplasts appeared disordered and lost their peripheral structure. The thylakoid membranes, starch granules and lipids from the plastoglobuli were distributed throughout the central vacuole. Rehydrated leaves of Slender Leaf and Nightshade showed the most significant disruption of the chloroplasts and their grana thylakoid membranes could not be recognized in Fig. 6(B and D). For Jute Mallow, the chloroplast structures were also significantly disrupted while some regions of organized thylakoid membranes could still be observed (Fig. 6(A)). For Cowpea and Amaranthus, the chloroplasts also lost their peripheral orientation and welldefined shape but the grana and stroma thylakoid membranes and plastoglobuli could still be recognized (Fig. 6(C and E)).

\section{Conclusions}

Moisture sorption isotherms of the ALVs gave insights into the rehydration capacity of five species of African leafy vegetables. Jute Mallow, Cowpea and Amaranthus did not rehydrate to the equilibrium moisture content of the fresh leaves upon drying 
at $40{ }^{\circ} \mathrm{C}$ and storage for one to two months. Light microscopy showed that for Jute Mallow and Cowpea the long palisade parenchyma cells in the fresh leaves could not fully rehydrate which resulted in a reduced thickness of the rehydrated leaves. Additionally, the kinetics of rehydration of dried leaves was significantly slower than that of the dehydration of the fresh leaves for these species. Organoleptic tests in a previous study, however, showed that there was no significant difference in preference between fresh and dried Jute Mallow and Cowpea leaves. ${ }^{11}$ For Amaranthus, the bundle sheath cellular organization could still be observed in the rehydrated leaves but the palisade cells also had a reduced thickness. In contrast, the microstructure, and particularly the chloroplast structure, of Jute Mallow, Cowpea and Amaranthus, was still partially intact. Chemical changes might also have occurred during storage, resulting in a modified material and incomplete rehydration.

Moisture sorption isotherms of Slender Leaf and Nightshade showed that these species could be rehydrated to the equilibrium moisture content of the fresh leaves upon dry storage. Light microscopy also confirmed rehydration to the same thickness as the fresh leaves and similar dehydration and rehydration kinetics for these species. While the palisade parenchyma cells were slightly shorter in the rehydrated leaves the spongy parenchyma region increased in thickness. The microstructure of the cells, however, was significantly disrupted for these species and the thylakoid membrane organization of the chloroplasts was lost. This suggests that the changes in the microstructure compensated for the rehydration capacity of the leaves. Nevertheless, the significantly increased amount of starch granules as was observed in the nanostructure of Cowpea and Nightshade leaves can explain their fibrous structure compared to the paste that is formed upon cooking of Jute Mallow and Slender Leaf (slimy). Whether the species were fibrous or slimy did not affect the moisture sorption characteristics.

Moisture sorption characteristics did not depend on the moisture content of the fresh leaves. The microbial safe moisture content of the five species of African leafy vegetables was determined using the GAB model and found to be $\leq 14 \%$ d.b. The monolayer moisture content was determined to be $\sim 4.5 \%$ d.b. for all species and this moisture does not participate in any deteriorative reactions. These results indicate that the same drying technology can be used for the effective preservation of a wide range of ALV species. Additionally, using superabsorbent polymers improves the energy efficient gentle drying conditions and ensures drying and storage of all species below their microbial safe moisture content. Combined with the high nutritional value for leaves dried at $40{ }^{\circ} \mathrm{C},{ }^{11}$ this shows that drying under controlled conditions is an effective method to preserve African leafy vegetables and fight hidden hunger and micronutrient deficiency in sub-Saharan Africa.

\section{Conflicts of interest}

There are no conflicts of interest to declare.

\section{Acknowledgements}

We acknowledge Prof. Ingo Burgert for providing access to the DVS instrument and Dr Erik V. Bachtiar and Philippe Grönquist for their help. We thank Prof. Consuelo De Moraes and Claude Fornallaz for providing greenhouse space at ETH Zurich. The authors acknowledge support of ScopeM/Swiss Federal Institute of Technology ETHZ. The SoLVeD project was funded by the Coop Research Program of the World Food System Center.

\section{References}

1 J. Gustavsson, I. Cederberg, U. Sonesson, R. Van Otterdijk and A. Meybeck, Global Food Losses and Food Waste Extent, Causes and Prevention, 2011.

2 D. N. Alusala, B. B. A. Estambale, P. Magnussen, H. Friis, A. I. Luoba and D. Mwaniki, Predictors of Serum Ferritin and Haemoglobin during Pregnancy, in a Malaria-Endemic Area of Western Kenya, Ann. Trop. Med. Parasitol., 2008, 102(4), 297-308, DOI: 10.1179/136485908X278874.

3 S. Brooker, P. J. Hotez and D. A. P. Bundy, HookwormRelated Anaemia among Pregnant Women: A Systematic Review, PLoS Neglected Trop. Dis., 2008, 2(9), e291.

4 N. P. Uusiku, A. Oelofse, K. G. Duodu, M. J. Bester and M. Faber, Nutritional Value of Leafy Vegetables of SubSaharan Africa and Their Potential Contribution to Human Health: A Review, J. Food Compos. Anal., 2010, 23(6), 499509, DOI: 10.1016/j.jfca.2010.05.002.

5 P. Woomer and M. Imbumi, Traditional Green Vegetables in Kenya, 2003.

6 I. F. Smith and P. Eyzaguirre, African leafy vegetables: their role in the World Health Organization's global fruit and vegetable initiative, Afr. J. Food, Agric., Nutr. Dev., 2007, 7(3), 1-8.

7 D. O. Mbuge, R. Negrini, L. O. Nyakundi, S. P. Kuate, R. Bandyopadhyay, W. M. Muiru, B. Torto and R. Mezzenga, Application of Superabsorbent Polymers (SAP) as Desiccants to Dry Maize and Reduce Aflatoxin Contamination, J. Food Sci. Technol., 2016, 53(8), 31573165, DOI: 10.1007/s13197-016-2289-6.

8 J. W. Muthomi, B. K. Mureithi, G. N. Chemining'wa, J. K. Gathumbi and E. W. Mutit, Aspergillus Species and Aflatoxin B1 in Soil, Maize Grain and Flour Samples from Semi-Arid and Humid Regions of Kenya, Int. J. AgriSci., 2012, 2(1), 22-34.

9 G. P. Mutuli and D. Mbuge, Drying Characteristics and Energy Requirement of Drying Cowpea Leaves and Jute Mallow Vegetables, Agric. Eng. Int. CIGR J., 2015, 17(4), 562-272.

10 M. P. Nawiri, H. Nyambaka and J. I. Murungi, Sun-Dried Cowpeas and Amaranth Leaves Recipe Improves $\beta$-Carotene and Retinol Levels in Serum and Hemoglobin Concentration among Preschool Children, Eur. J. Nutr., 2013, 52(2), 583-589, DOI: 10.1007/s00394-012-0360-2.

11 G. P. Mutuli and D. Mbuge, Effect of Drying on the Nutritional and Organoleptic Characteristics of African 
Leafy Vegetables, Jute Mallow (Corchorus Olitorius L.) and Cowpea (Vigna Unguiculata), J. Biosyst. Eng., 2018, 43(3), 211-218.

12 B. L. Rockland, Influence of Water Activity on Food Product Quality and Stability, Food Technol., 1980, 34, 42-51.

13 A. H. Al-Muhtaseb, W. A. M. McMinn and T. R. A. Magee, Moisture Sorption Isotherm Characteristics of Food Products: A Review, Food Bioprod. Process., 2002, 80(2), 118128, DOI: 10.1205/09603080252938753.

14 J. Chirifie and P. Buera, Water Activity, Glass Transition and Microbial Stability in Concentrated/Semimoist Food Systems, J. Food Sci., 2018, 59(5), 921-927, DOI: 10.1111/ j.1365-2621.1994.tb08159.x.

15 E. E. Thybring, L. G. Thygesen and I. Burgert, Hydroxyl Accessibility in Wood Cell Walls as Affected by Drying and Re-Wetting Procedures, Cellulose, 2017, 24(6), 2375-2384, DOI: 10.1007/s10570-017-1278-x.

16 M. Kouhila, A. Belghit, M. Daguenet and B. C. Boutaleb, Experimental Determination of the Sorption Isotherms of Mint (Mentha Viridis), Sage (Salvia Officinalis) and Verbena (Lippia Citriodora), J. Food Eng., 2001, 47(4), 281287, DOI: 10.1016/S0260-8774(00)00130-8.

17 M. Caurie, Derivation of Full Range Moisture Sorption Isotherms, in Water Activity: Influences on Food Quality, ed. L. B. Rockland, G. F. Stewart, Academic Press, 1981, pp. 63-87.

18 C. Engels, M. Hendrickx and P. Tobback, Limited Multilayer Desorption of Brown, Parboiled Rice, Int. J. Food Sci. Technol., 2018, 22(3), 219-223, DOI: 10.1111/j.13652621.1987.tb00481.x.

19 H. A. Iglesias and J. Chirife, Prediction of the Effect of Temperature on Water Sorption Isotherms of Food Material, Int. J. Food Sci. Technol., 2018, 11(2), 109-116, DOI: $10.1111 / \mathrm{j} .1365-2621.1976 . t b 00707 . x$.

20 O. Bensebia and K. Allia, Analysis of AdsorptionDesorption Moisture Isotherms of Rosemary Leaves, J. Appl. Res. Med. Aromat. Plants, 2016, 3(3), 79-86, DOI: 10.1016/j.jarmap.2016.01.005.

21 C. J. Willmott, Advantages of the Mean Absolute Error (MAE) over the Root Mean Square Error (RMSE) in Assessing Average Model Performance, Clim. Res., 2005, 30(1), 79-82.

22 K. Y. Foo and B. H. Hameed, Insights into the Modeling of Adsorption Isotherm Systems, Chem. Eng. J., 2010, 156(1), 2-10, DOI: 10.1016/j.cej.2009.09.013.

23 D. R. Milićević, M. Škrinjar and T. Baltić, Real and Perceived Risks for Mycotoxin Contamination in Foods and
Feeds: Challenges for Food Safety Control, Toxins, 2010, 2(4), 572-592, DOI: 10.3390/toxins2040572.

24 A. H. Al-Muhtaseb, W. A. M. McMinn and T. R. A. Magee, Water Sorption Isotherms of Starch Powders: Part 1: Mathematical Description of Experimental Data, J. Food Eng., 2004, 61(3), 297-307, DOI: 10.1016/S0260-8774(03) 00133-X.

25 C. J. Lomauro, A. S. Bakshi and T. P. Labuza, Evaluation of Food Moisture Sorption Isotherm Equations Part I: Fruit, Vegetable and Meat Products, LWT-Food Sci. Technol., 1985, 18(2), 111-117.

26 S. Brunauer, L. S. Deming, W. E. Deming and E. Teller, On a Theory of the van Der Waals Adsorption of Gases, J. Am. Chem. Soc., 1940, 62(7), 1723-1732.

27 N. Arslan and H. Toğrul, The Fitting of Various Models to Water Sorption Isotherms of Tea Stored in a Chamber under Controlled Temperature and Humidity, J. Stored Prod. Res., 2006, 42(2), 112-135, DOI: 10.1016/j.jspr.2005.01.001.

28 D. Argyropoulos, R. Alex, R. Kohler and J. Müller, Moisture Sorption Isotherms and Isosteric Heat of Sorption of Leaves and Stems of Lemon Balm (Melissa Officinalis L.) Established by Dynamic Vapor Sorption, LWT-Food Sci. Technol., 2012, 47(2), 324-331, DOI: 10.1016/j.lwt.2012.01.026.

29 R. Martínez-Las Heras, A. Heredia, M. L. Castelló and A. Andrés, Moisture Sorption Isotherms and Isosteric Heat of Sorption of Dry Persimmon Leaves, Food Biosci., 2014, 7, 88-94, DOI: 10.1016/j.fbio.2014.06.002.

30 P. A. Nakata, Advances in Our Understanding of Calcium Oxalate Crystal Formation and Function in Plants, Plant Sci., 2003, 164(6), 901-909, DOI: 10.1016/S0168-9452(03)00120-1.

31 B. Libert and V. R. Franceschi, Oxalate in Crop Plants, J. Agric. Food Chem., 1987, 35(6), 926-938, DOI: 10.1021/ jf00078a019.

32 M. F. Quartacci, M. Forli, N. Rascio, F. D. Vecchia, A. Bochicchio and F. Navari-Izzo, Desiccation-Tolerant Sporobolus Stapfianus: Lipid Composition and Cellular Ultrastructure during Dehydration and Rehydration, J. Exp. Bot., 1997, 48(311), 1269-1279.

33 F. D. Vecchia, T. El Asmar, R. Calamassi, N. Rascio and C. Vazzana, Morphological and Ultrastructural Aspects of Dehydration and Rehydration in Leaves of Sporobolus Stapfianus, Plant Growth Regul., 1998, 24(3), 219-228, DOI: 10.1023/A:1005853527769.

34 S. Jobling, Improving Starch for Food and Industrial Applications, Curr. Opin. Plant Biol., 2004, 7(2), 210-218, DOI: 10.1016/J.PBI.2003.12.001. 